\title{
Microcystin-LR-Triggered Neuronal Toxicity in Whitefish Does Not Involve MiR124-3p
}

\author{
Maciej Florczyk ${ }^{1}$ (D) Paweł Brzuzan ${ }^{1} \cdot$ Alicja Łakomiak $^{1}$ • Ewa Jakimiuk ${ }^{2} \cdot$ Maciej Woźny $^{1}$
}

Received: 25 February 2018 / Revised: 28 May 2018 / Accepted: 30 May 2018 / Published online: 7 June 2018

(C) The Author(s) 2018

\begin{abstract}
Microcystin-LR (MC-LR) is a potent hepatotoxin that has also been pointed out of causing neurotoxicity, but the exact mechanisms of action still remain ambiguous and need to be elucidated. Data from studies on mammals show that pathology of astrocyte cells points to perturbations of microRNA signaling. Glial fibrillary acidic protein (GFAP), a neuronal cell/astrocyte-specific protein, and a microRNA-124-3p (MiR124-3p) are among putative triggers and regulators of neuronal cell/astrocyte reactivity. In the present study on whitefish (Coregonus lavaretus), we found that gfap mRNA contains a putative target site for MIR124-3p, to potentially affect its expression changes. qPCR expression study of gfap:MiR124-3p pair in the midbrain of juvenile whitefish, during 28 days of exposure to a repeated subacute dose of MC-LR (100 $\mathrm{g} \mathrm{kg}^{-1}$ body mass), showed marginally significant up-regulation of gfap only on the 7th day of exposure period which suggests neuronal toxicity. During the whole exposure period, neither midbrain nor blood plasma levels of MiR124-3p were changed. Furthermore, double luciferase gene reporter assay confirmed the lack of MiR124-3p involvement in mediating control over gfap mRNA expression. These data show that, although MC-LR may trigger neuronal toxicity in whitefish, this does not involve MiR124-3p in response to the treatment.
\end{abstract}

Keywords microRNA $\cdot$ Neurotoxicity $\cdot$ Gliosis $\cdot$ Circulating microRNA

\section{Introduction}

Microcystins (MCs) are a challenging group of cyclic heptapeptide hepatotoxins for which a substantial gap in knowledge persists regarding the underlying molecular mechanisms of organ toxicity and injury. Microcystin-LR (MC-LR) is a commonly acting potent environmental agent that has gained a role in causing neurotoxicity. The adverse effects entailed by MC-LR exposure include both behavioral changes, such as different swimming habits and uncommon daily

Electronic supplementary material The online version of this article (https://doi.org/10.1007/s12640-018-9920-4) contains supplementary material, which is available to authorized users.

Maciej Florczyk

maciej.florczyk@uwm.edu.pl

1 Department of Environmental Biotechnology, Faculty of Environmental Sciences, University of Warmia and Mazury in Olsztyn, ul. Słoneczna 45G, 10-709 Olsztyn, Poland

2 Division of Veterinary Prevention and Feed Hygiene, Faculty of Veterinary Medicine, University of Warmia and Mazury in Olsztyn, ul. Oczapowskiego 13, 10-950 Olsztyn, Poland activity (Baganz et al. 1998, 2004; Cazenave et al. 2008), and altered brain physiology (i.e., altered levels of proteins involved in the cytoskeleton assemblage, dysregulated signal transduction, protein degradation, metabolism, transport, apoptosis, and translation) (Wang et al. 2010). In mammals, damage to the central nervous system (CNS) is reflected by increased expression of glial fibrillary acidic protein (GFAP). GFAP/Gfap is an intermediate filament protein expressed by numerous cells in the CNS, including mature astrocytes (Middeldorp and Hol 2011). Following various kinds of injury to the CNS, including chemical insult, astrocytes become reactive and respond in a typical manner termed astrogliosis (Sofroniew and Vinters 2010). Astrogliosis is characterized by rapid synthesis of gfap resulting in the formation of a glial scar, a common marker of damage to the CNS (Brenner 2014).

Although the exact mechanisms of action still remain ambiguous, the range of observed neuronal defects points to perturbations of epigenetic factors such as microRNA (miRNA) signaling. MiRNAs are small (19-23 nucleotides), single-stranded non-coding RNAs that act as post-transcriptional regulators of gene expression (Moxon et al. 2008). They negatively modulate up to $60 \%$ of mammalian protein-coding genes by interacting with response elements in the $3^{\prime}$ untranslated regions ( $3^{\prime}$ UTRs) 
of mRNAs and target the mRNAs for degradation and/or inhibit their translation (Bartel 2004; Friedman et al. 2009). Our previous studies on MC-LR effects on fish miRnome have revealed that MC-LR was capable of modulating expression of several microRNAs, members of RNA interference system, in the liver of challenged fish (Brzuzan et al. 2012, 2016; Łakomiak et al. 2016), which points out their mechanistic involvement in the toxicity mechanism. Since molecular background of MC-LR toxicity seems to be similar in different tissues, it was reasonable to assume that similar effects will emerge in the brain. MiRNA profiling of experimental stroke brains has shown alterations in many individual miRNAs, and bioinformatics tools revealed putative functional miRNA:mRNA pairs (Saul et al. 2014). The observation that miRNA levels in the nervous system were changed by MCLR (Saul et al. 2014) prompted us to investigate the role of fish microRNAs in the context of brain-specific MC-LR toxicity. Moreover, recent studies have shown that disrupted expression of GFAP is associated with altered levels of miRNAs such as MiR125b (Pogue et al. 2010) and MiR145 (Wang et al. 2015). MiR3099 has been shown to target GFAP in the mouse brain (Abidin et al. 2017).

The possibility that MiR124 is able to induce proliferation of reactive astrocytes has recently been demonstrated in mice (Hamzei Taj et al. 2016). MiR124 is the most abundant miRNA in the nervous system of mammals and fish, and it is considered as a nervous system-specific miRNA (Kapsimali et al. 2007; Mishima et al. 2007). Noteworthy, the MIR124 family members were detected in 46 animal species, from Caenorhabditis to Homo sapiens (Guo et al. 2009). Their abundance in embryonic and adult cortical tissues of various mammalian species range from 5 to $48 \%$ of all miRNAs expressed, suggesting that it has a key function in the CNS (Lagos-Quintana et al. 2002; Landgraf et al. 2007). MiR124 was proven to regulate brain development, as well as it is enriched in mature brain tissue, where it plays important roles in neuronal regulation. MiR124 has been shown to be downregulated in CNS pathologies, such as glioma and medulloblastoma, suggesting its possible involvement in brain tumor progression. On the other hand, MiR124 was found to increase neuronal survival and functional improvement of the neurological deficits (Hamzei Taj et al. 2016) and enhance brain repair in Parkinson's disease (Saraiva et al. 2016). Mammals treated with MiR124 developed a significantly reduced glial scar area after occlusion of the right middle cerebral artery (Doeppner et al. 2013). More recently, it has been shown that MIR124-3p target sequence in mediated gene transfer restored astrocyte activity in rats, thus showing its utility in studying the miRNA contribution to physiological and pathophysiological processes in the brain (Taschenberger et al. 2017).

Since the above studies link changes in brain GFAP and miRNA expression in mammals, the goals of this study were to dissect involvement of this miRNA:mRNA pair in fish exposed to known neurotoxic environmental agent microcystin-LR (Li et al. 2014). First, we were curious whether there is a functional relationship between expression of MiR124-3p and gfap mRNA in vitro, thereby suggesting the possibility of interaction and involvement of this miRNAmRNA pair in vivo in response to neuronal cells to stressing conditions. To address this issue, we determined nucleotide sequence of the whitefish gfap mRNA. Then, using computational approach, we revealed that the 3'UTR of whitefish gfap mRNA contains one putative MiR124-3p response element. Secondly, we investigated whether long-term exposure of whitefish to MC-LR would cause alterations in the expression of either molecule in brains similar to those observed in mammals. To this end, we profiled expression levels of MiR124-3p and gfap mRNA in the brains of whitefish treated for $1 / 3,1,2$, 7, 14, and 28 days with a subacute dose of MC-LR. Additionally, we examined whether plasma levels of MiR124-3p could relate to disrupted gfap expression in the brain and possibly serve as a biomarker of MC-LR exposure. Finally, to confirm the functional involvement of MiR1243p:gfap pair, a dual-luciferase reporter assay was performed.

\section{Material and Methods}

\section{Determining gfap CDNA Sequence of European Whitefish}

We first obtained a partial gfap cDNA sequence of European whitefish, using a designed set of primers (Cla-gfap-F1, Clagfap-R1; Supplementary File 1) based on the S. salar EST sequence available at GenBank (accession no. GE794087.1). Initial PCR amplification of a starting DNA sequence was conducted using Phusion Flash PCR Master Mix (Thermo Scientific) with the following cycling conditions: $98^{\circ} \mathrm{C}$ for $10 \mathrm{~s} ; 30$ cycles at $98^{\circ} \mathrm{C}$ for $1 \mathrm{~s}, 60^{\circ} \mathrm{C}$ for $5 \mathrm{~s}, 72^{\circ} \mathrm{C}$ for $10 \mathrm{~s}$; followed by $72{ }^{\circ} \mathrm{C}$ for $1 \mathrm{~min}$. Following electrophoresis, a band observed at the expected size was cut out and purified using the PureLink ${ }^{\mathrm{TM}}$ Quick Gel Extraction and PCR Purification Combo Kit (Invitrogen). The putative cDNA fragment of gfap mRNA was then sequenced under contract (Genomed).

The partial gfap cDNA sequence was subsequently used as a query in a BLAST search against the sequence deposited in sequence read archive (SRA), accession no. SRX465095, obtained from three pooled normal embryos of lake whitefish (Coregonus clupeaformis). The revealed sequence of putative gfap of lake whitefish was used as a template to design other sets of primers: Cla-gfap-2-F2 and Cla-gfap-2-R2, Cla-gfap2-F3 and Cla-gfap-2-R3, and Cla-gfap-2-F4 and Cla-gfap-2R4 (Supplementary File 1). These primers were used to amplify the partial 5'UTR, entire coding sequence, and partial 3' 
UTR of European whitefish gfap, respectively. PCR was carried out in a final volume of $25 \mu \mathrm{L}$ as follows: $1 \mu \mathrm{L}$ of cDNA as template, $12.5 \mu \mathrm{L}$ of $2 \times$ DreamTaq Green PCR Master Mix (Thermo Scientific), $0.5 \mu \mathrm{M}$ of forward and reverse primers (Cla-gfap-2-F2 and Cla-gfap-2-R2, or Clagfap-2-F3 and Cla-gfap-2-F3, or Cla-gfap-2-F4 and Cla-gfap2-R4), and $9.5 \mu \mathrm{L}$ of nuclease-free water. The PCR conditions were 1 cycle at $95^{\circ} \mathrm{C}$ for $3 \mathrm{~min}$ followed by 30 cycles at $95^{\circ} \mathrm{C}$ for $30 \mathrm{~s}$, optimal annealing temperature (as indicated in Supplementary File 1) for $30 \mathrm{~s}$ and $72{ }^{\circ} \mathrm{C}$ for $1 \mathrm{~min}$. Final extension was carried out at $72{ }^{\circ} \mathrm{C}$ for $30 \mathrm{~min}$. The PCR products were cloned using the InsTAclone PCR Cloning Kit (Thermo Scientific) according to the manufacturer's protocol, with some modifications. PCR amplicons were ligated into $\mathrm{pTZ57R/T}$ vector, afterwards the ligation mixtures were transformed into the JM109 competent Escherichia coli cells (Promega, USA) using a heat shock $\left(42{ }^{\circ} \mathrm{C}\right)$ transformation method. The resulting transformants were spread on LB agar plates containing X-gal (40 $\mathrm{g} / \mathrm{mL})$, IPTG $(40 \mu \mathrm{g} / \mathrm{mL})$, and ampicillin $(100 \mu \mathrm{g} / \mathrm{mL})$ and incubated overnight at $37^{\circ} \mathrm{C}$. Insert-positive colonies were picked and inoculated into $4 \mathrm{~mL}$ of LB with $100 \mu \mathrm{g} / \mathrm{mL}$ of ampicillin. After incubation at $37^{\circ} \mathrm{C}$ for $16 \mathrm{~h}$, the plasmids DNA were isolated using a Plasmid Mini Kit (A\&A Biotechnology) and sequenced (Genomed). Nucleotide sequences were then assembled using Clustal $\mathrm{X}$ 2.1 software into a cDNA sequence of 2160-bp length. This allowed further MiR124-3p target site identification with Segal Lab software.

The obtained gfap cDNA sequence was further analyzed by RegRNA 2.0 web server (Chang et al. 2013) to identify the homology of functional RNA motifs and sites, and to align with gfap transcript of zebrafish (Ensembl accession no. ENSDART00000028270.6) to predict potential exon-exon junction. In order to find the open reading frame and to acquire the amino acid sequence, cDNA sequence was subjected to the ORF finder software (Wheeler et al. 2004). To identify the domain organization of deduced Gfap protein sequence, the InterPro v. 53 (Mitchell et al. 2015), SMART (Letunic et al. 2015), and Conserved Domains Search (Marchler-Bauer et al. 2015) were used. The molecular weight (MW) and isoelectric point $(\mathrm{pI})$ were determined using the Compute $\mathrm{pI} / \mathrm{Mw}$ tool (Gasteiger et al. 2005). The sequence of whitefish gfap has been deposited in GenBank under accession no. MG182670.

\section{Phylogenetic Analysis of Whitefish Gfap}

To gain insight into the evolutionary relationship of Gfap, the deduced amino acid sequence was compared with those of other vertebrates deposited in NCBI database: XP_02141413 (O. mykiss), XP_01404923 (S. salar), AAH68410.1 (D. rerio), AAB22581.1 ( $\bar{H}$. sapiens), and P03995.4 (M. musculus). The sequences were aligned using Clustal W (Larkin et al. 2007) and the output was visualized using BoxShade 3.21 software (www.
ch.embnet.org/software/BOX_form.html). The sequences were also compared using Clustal X 2.1 software to create the percent identity matrix. The phylogenetic tree was constructed using the neighbor-joining method implemented in MEGA 6.06 software (Tamura et al. 2013) with default settings and 1000 bootstrap replicates. The tree was rooted with CED-9 sequences from Caenorhabditis elegans (GenBank accession no. NP_499284).

\section{Construction of Luciferase Reporter Plasmids for Luciferase Assay}

To investigate whether MiR124-3p can regulate the expression of whitefish gfap, three types of luciferase reporter plasmids were prepared based on the pmirGLO Dual-Luciferase miRNA Target Expression Vector (Promega). To construct the gfap-3'UTR-wt plasmid, the entire 3'UTR region of whitefish gfap, obtained in this study, which contains putative MiR124$3 p$ response element(s), was amplified by PCR using $1 \mu \mathrm{L}$ of cDNA template, $12.5 \mu \mathrm{L}$ of $2 \times$ Phusion Flash PCR Master Mix (Thermo Scientific), 0.5 $\mu \mathrm{M}$ of gfap-3'UTR-F-DraI and gfap-3' UTR-R-XbaI primers, and $9.5 \mu \mathrm{L}$ of nuclease-free water. Cycling conditions were as follows: $98{ }^{\circ} \mathrm{C}$ for $10 \mathrm{~s} ; 30$ cycles at $98{ }^{\circ} \mathrm{C}$ for $1 \mathrm{~s}, 62^{\circ} \mathrm{C}$ for $5 \mathrm{~s}$, and $72{ }^{\circ} \mathrm{C}$ for $25 \mathrm{~s}$; followed by $72{ }^{\circ} \mathrm{C}$ for $2 \mathrm{~min}$. The gel-purified (Invitrogen) product was double digested with $\mathrm{XbaI}$ and DraI restriction enzymes (Thermo Scientific) and cloned into a multiple cloning site of the pmirGLO downstream of the firefly luciferase gene (gfap-3' UTR-wt). Additionally, plasmids containing mutations in the sequence complementary to the seed region of gfap (gfap-3' UTR-mut, positive control) were also generated. The resulting plasmids were used to transform the competent E. coli JM109 cells (Promega) via the heat shock method. All subsequent steps up to isolation of plasmids from the liquid bacterial culture were carried out as described in the "Determining gfap cDNA sequence of European whitefish" section. All plasmids were confirmed by sequencing (Genomed). Sequences of each oligonucleotides used for generation of luciferase reporter plasmids are provided in Supplementary File 1.

\section{Cell Culture}

Human Embryonic Kidney 293T (HEK-293T) cells were purchased from the American Type Culture Collection (ATCC, USA) and maintained in Dulbecco's Modified Eagle's Medium/Nutrient Mixture F-12 Ham (DMEM/F12, Sigma-Aldrich) supplemented with $10 \%$ heat-inactivated fetal bovine serum, $2 \mathrm{mM}$ L glutamine, $100 \mathrm{U} / \mathrm{mL}$ penicillin, and $100 \mu \mathrm{g} / \mathrm{mL}$ streptomycin (Sigma-Aldrich). HEK$293 \mathrm{~T}$ cells were incubated at $37{ }^{\circ} \mathrm{C}$ in a humidified $5 \%$ $\mathrm{CO}_{2}$ incubator. 


\section{Cell Transfection and Dual-Luciferase Reporter Assay}

At $24 \mathrm{~h}$ prior to transfection, the HEK-293T cells were plated at $8 \times 10^{4}$ cells per well in 24 -well dishes. Transient transfection was performed at $\sim 80 \%$ confluence using the FuGENE HD transfection reagent (Promega) according to the manufacturer's protocol. For each transfection experiment, $500 \mathrm{ng}$ of the appropriate reporter construct (gfap-3'UTR-wt, gfap-3' UTR-mut, or unmodified pmirGLO vector) and $60 \mathrm{nM}$ of MiR124-3p mimic or Negative Control (Dharmacon, USA) were used. For each plasmid, three independent transfection experiments were performed and each was done in quadruplicate. Twenty-four hours after, transfection cells were harvested and assayed for firefly and Renilla luciferase activities by the Dual-Luciferase Reporter Assay System (Promega) in a GloMax-Multi+ Microplate Multimode Reader (Promega), according to the manufacturer's instruction. Relative luciferase activity was compared using the ratio of firefly and Renilla luciferase activity (F/R) of MiR124-3p to the Negative Control ratio of firefly and Renilla luciferase activity $(\mathrm{F} / \mathrm{R})$.

\section{Cell Viability Assay}

To measure cell viability, CellTiter-Glo Luminescent Cell Viability Assay was used (Promega). It measures the viability of cells based upon the quantification of cellular ATP levels. The assay relies upon the generation of a luminescent signal which is proportional to the amount of ATP and thus the number of cells that are present. For each plasmid, one additional transfection experiment was performed in quadruplicate. To obtain a value for background luminescence, control wells containing medium without cells were prepared. After transfection procedure, the volume of CellTiter-Glo Reagent equal to the volume of cell culture medium present in each well was added. Contents were mixed for $2 \mathrm{~min}$ to induce cell lysis and incubated at room temperature for $10 \mathrm{~min}$. Luminescence signal was measured in GloMax-Multi+ Microplate Multimode Reader (Promega).

\section{Fish Handling and Exposure}

Hatchery-reared juveniles of whitefish (Coregonus lavaretus, $98.8 \pm 8.5 \mathrm{~g}$ mean weight, $24.0 \pm 0.7 \mathrm{~cm}$ mean length) were held at the Department of Salmonid Research in Rutki (Inland Fisheries Institute in Olsztyn, Poland). The fish were acclimated for 2 weeks at $10^{\circ} \mathrm{C}$. During the acclimation period, the whitefish were fed four times a day (Skretting). After acclimatization, the fish were deprived of food for 2 days, then anesthetized by immersion in etomidate solution prior to injection. The MC-LR dosage was selected based on our earlier studies in whitefish (Brzuzan et al. 2016; Woźny et al. 2016). Chemical standard of MC-LR (purity $\geq 95 \%$; HPLC) was obtained from Enzo Life Sciences (Enzo Biochem, Inc.) and dissolved in saline solution $(0.8 \% \mathrm{NaCl})$ as a vehicle solvent. The prepared solution contained $10 \mu \mathrm{g}$ of MC-LR per $200 \mu \mathrm{L}$ of volume set for each intraperitoneal injection. Exposed whitefish individuals received single intraperitoneal injections $(0.5 \times 25 \mathrm{~mm}$ needle $)$ of MC-LR $\left(100 \mu \mathrm{g} \mathrm{kg}^{-1}\right.$ body wt.; $10 \mu \mathrm{g}$ per $200 \mu \mathrm{L}^{-1}$ of $0.8 \% \mathrm{NaCl}$ ), and in the same way, control fish were injected with an equal volume of saline solution alone. Following injection, the fish were placed in separate single-pass flow-through tanks supplied with system (surface) water for $48 \mathrm{~h}(\mathrm{pH} 7.5$; oxygen saturation $>90 \%$; ammonium $<0.134 \mathrm{mg} \mathrm{L}^{-1}$ ). The intraperitoneal injections of MC-LR or saline were repeated on days 7, 14, and 21. Finally, six whitefish sampled immediately prior to placing in flowthrough tanks were taken as an initial control $(0 \mathrm{~h})$. Water temperature was measured once a day. The $95 \%$ confidence interval of the temperature in the tanks with exposed and control fish was $8-9{ }^{\circ} \mathrm{C}$. All animals used in this study were handled in accordance with the regulations set forth by the Local Ethical Commission in Olsztyn (resolution No. 100/ 2011 issued on 23rd of November 2011).

\section{Collection of Fish Tissue and Plasma Samples}

At the times of collection ( $0 \mathrm{~h}$ and after $1 / 3$ days, 1 days, 2 days, 7 days, 14 days, 28 days), the fishes were anesthetized with etomidate solution and around $2 \mathrm{~mL}$ of whole blood was taken from the caudal vein using S-Monovette K3 EDTA (Sarstedt). Then, the fish were killed and the brain was dissected out and preserved in RNAlater (Sigma-Aldrich). After collection, the blood was mixed by gently inverting the tube several times and immediately centrifuged at $4000 \times \mathrm{g}$ at room temperature for $5 \mathrm{~min}$. The plasma layer (approximately $400 \mu \mathrm{L}$ ) from the top of the tube was transferred into a fresh tube. Plasma was stored at $-20{ }^{\circ} \mathrm{C}$ during sample collection, shipped on dry ice, and stored at $-80^{\circ} \mathrm{C}$ in the laboratory until next procedures.

\section{Extraction and Reverse Transcription of Total RNA from Brain Tissue}

Total RNA was extracted from the midbrain (approximately $20 \mathrm{mg}$ ) from control and MC-treated whitefish using a mirVana isolation kit (Life Technologies) according to the manufacturer's protocol. Briefly, $200 \mu \mathrm{L}$ of Lysis/Binding Buffer was added. Samples were vortexed vigorously for $1 \mathrm{~min}$. Then, $20 \mu \mathrm{L}$ of miRNA Homogenate Additive was added and mixed by inverting the tube several times before it was left on ice for $10 \mathrm{~min}$. Next, $200 \mu \mathrm{L}$ of AcidPhenol:Chloroform was added and the mixture was vortexed for $1 \mathrm{~min}$. To separate the aqueous and organic phases, the tubes were centrifuged for $5 \mathrm{~min}$ at maximum speed $(10,000 \times \mathrm{g})$. 
About $200 \mu \mathrm{L}$ of upper phase was then transferred into a fresh tube. Next, 1.25 volumes of $99.8 \%$ ethanol at room temperature were added, and the entire solution was transferred into individual filter cartridges before centrifugation for $30 \mathrm{~s}$ at $10000 \times g$. Initial washing was conducted with $700 \mu \mathrm{L}$ of Washing Buffer 1 , followed by two washes with $500 \mu \mathrm{L}$ of Washing Buffer $2 / 3$. RNA was eluted from the washed filter cartridges with $40 \mu \mathrm{L}$ of preheated $\left(95^{\circ} \mathrm{C}\right)$ Elution Solution. The extracted RNA was immediately used in the next step. For mRNA expression studies, total RNA was DNAse treated, according to the manufacturer's protocol (Turbo DNAse; Ambion; USA). Reverse transcription (RT) was then directly carried out using a RevertAid First Strand cDNA synthesis kit (Thermo Scientific; USA). The cDNA synthesis reaction contained $1 \mu \mathrm{g}$ of DNAse-treated total RNA and $5 \mu \mathrm{M}$ of oligo $(\mathrm{dT})_{18}$ primer. After optional incubation $\left(65{ }^{\circ} \mathrm{C}\right.$ for $5 \mathrm{~min}$ ), the samples were chilled on ice and the following components were added: $4 \mu \mathrm{L}$ of $5 \times$ Reaction Buffer, $20 \mathrm{U}$ of RiboLock RNase Inhibitor, $1 \mathrm{mM}$ of dNTP mix, and $200 \mathrm{U}$ of RevertAid M-MuLV Reverse Transcriptase. To check for DNA contamination, two additional control reactions were run, one with all RT components except the enzyme (RT-), and the other with DNAse-treated RNA and no other reagents (NTC). The reaction was carried out at $42{ }^{\circ} \mathrm{C}$ for $60 \mathrm{~min}$, and then terminated by heating at $70{ }^{\circ} \mathrm{C}$ for $5 \mathrm{~min}$. Synthesized cDNA samples were stored at $-80^{\circ} \mathrm{C}$ and thawed only once, just before amplification.

To profile MiR124-3p expression, we designed a protocol based on polyadenylated RNA and stem-loop reverse transcription (Biggar et al. 2014; Brzuzan et al. 2016). miRNA polyadenylation was performed using a polymerase tailing kit (Epicentre). Reactions were prepared with $1 \mu \mathrm{L}$ of $10 \times$ polyadenylate polymerase buffer, $1 \mu \mathrm{L}$ of adenosine triphosphate (ATP, $10 \mathrm{mM}), 0.5 \mu \mathrm{L}$ of Escherichia coli poly(A)polymerase (4 U), $1 \mu \mathrm{g}$ of total RNA, and RNasefree water to a final volume of $10 \mu \mathrm{L}$. Reaction mixtures were incubated at $37^{\circ} \mathrm{C}$ for $30 \mathrm{~min}$, followed by $95^{\circ} \mathrm{C}$ for $5 \mathrm{~min}$ to terminate the adenylation, and then transferred directly to ice. Reverse transcription was performed as described above, with one modification. Instead of using oligo(dT)18 primer, an aliquot of $10 \mu \mathrm{L}$ of polyadenylated RNA from the previous step was incubated with $1 \mu \mathrm{L}$ of $100 \mu \mathrm{M}$ universal stem-loop RT primer (5'-CTC ACA GTA CGT TGG TAT CCT TGT GAT GTT CGA TGC CAT ATT GTA CTG TGA GTT TTT TTT TVN-3'), followed by already described procedure. Synthesized cDNA samples were diluted $(20 \times)$ stored at $80^{\circ} \mathrm{C}$ and thawed only once, just before amplification.

\section{miRNA Extraction from Plasma}

Total RNA was extracted from $80 \mu \mathrm{L}$ of plasma from control and MC-treated whitefish using a mirVana isolation kit (Life Technologies) according to the manufacturer's protocol with modifications. After thawing, samples were briefly centrifuged and 10 volumes of Lysis/Binding Buffer were added. Samples were vortexed vigorously for $1 \mathrm{~min}$. To normalize sample-tosample variation in the RNA isolation procedure, an exogenous spike-in control of $3 \mu \mathrm{L}$ of synthetic $5 \mathrm{nM}$ cel-MiR39-3p (5'-UCACCGGGUGUAA AUCAGCUUG-3') was added. Then, $80 \mu \mathrm{L}$ of miRNA Homogenate Additive was added and mixed by inverting the tube several times before it was left on ice for $10 \mathrm{~min}$. Next, $800 \mu \mathrm{L}$ of Acid-Phenol:Chloroform was added and the mixture was vortexed for $1 \mathrm{~min}$. To separate the aqueous and organic phases, the tubes were centrifuged for $5 \mathrm{~min}$ at maximum speed $(10,000 \times g)$ at room temperature. About $300 \mu \mathrm{L}$ of upper phase was then transferred into a fresh tube. Next, 1.25 volumes of $99.8 \%$ ethanol at room temperature were added, and the entire solution was transferred into individual filter cartridges before centrifugation for $30 \mathrm{~s}$ at $10000 \times g$. Initial washing was conducted with $700 \mu \mathrm{L}$ of Washing Buffer 1 , followed by two washes with $500 \mu \mathrm{L}$ of Washing Buffer $2 / 3$. RNA was eluted from the washed filter cartridges with $40 \mu \mathrm{L}$ of preheated $\left(95^{\circ} \mathrm{C}\right)$ Elution Solution. The extracted RNA was immediately used in the next steps described above.

\section{qPCR Analysis}

Real-time PCR was used to determine gfap mRNA and MiR124-3p levels in midbrain and plasma of control and MC-LR-treated whitefish. Reactions were carried out in final volumes of $20 \mu \mathrm{L}$, consisting of $10 \mu \mathrm{L}$ of Power SYBR Green PCR Master Mix (Life Technologies, USA), $0.25 \mu \mathrm{M}$ of each primer (forward and reverse; Supplementary File 1), $1 \mu \mathrm{L}$ of cDNA template (see "Determining gfap cDNA Sequence of European Whitefish" and "Phylogenetic Analysis of Whitefish Gfap"), and $7 \mu \mathrm{L}$ of PCR-grade water. Amplification was performed on an ABI 7500 Real-time PCR System thermocycler (Applied Biosystems; USA) with the following conditions: $95^{\circ} \mathrm{C}$ for $10 \mathrm{~min}$, then 45 cycles of $95{ }^{\circ} \mathrm{C}$ for $15 \mathrm{~s}$ and $60{ }^{\circ} \mathrm{C}$ for $1 \mathrm{~min}$. The reaction for each sample was carried out in duplicates. No template controls (NTCs) were included to test for the possibility of crosscontamination. To check the quality of each PCR products, melting curve analyses were additionally performed after each run.

Quantitative cycle $(\mathrm{Cq})$ values obtained from qPCR were converted into template concentration using a standard curve plot ( $\mathrm{Cq}$ versus log DNA concentration), following the approach of Arukwe (2006) as described by Spachmo and Arukwe (2012). To generate the standard curve, plasmids with target sequences were used to prepare a series of six tenfold dilutions and then served as the template in qPCR. Cq values obtained for each dilution were plotted against the log of the DNA concentration and then used to extrapolate the unknown samples to absolute numbers. In order to calculate relative expression, the absolute numbers of all analyzed samples 
were divided by the geometric mean obtained from the control group; and these values were further presented as the expression ratio $(R)$. Based on the results obtained for the standard curve, PCR efficiency was also calculated according to the following equation: $E=10^{[-1 / \text { slope }]}$ (Pfaffl et al. 2002).

\section{Statistical Analysis}

The gene ( $g$ fap; MiR124-3p) expression data obtained from the treatment study was tested for statistical differences using an unpaired $t$ test (two-tailed) to compare the values determined in control fish cohort with those of the exposed whitefish at the respective time points. To test for normality of the distribution of the samples compared, the non-parametric Kolmogorov-Smirnov (K-S) test was used. In cases where the K-S test failed, two-sample Mann-Whitney test was applied. The correlation between expression of MiR124-3p in the brain and peripheral blood serum was analyzed using the Pearson method. All calculations and statistical analyses were performed using GenEx 5 Professional software (MultiD Analyses).

\section{Results}

\section{Gfap in Whitefish Is a Structurally Conserved Protein}

The obtained cDNA sequence of whitefish gfap comprised 2160 base pairs, including partial 5'UTR (38 bp) and partial 3'UTR (748 bp) (Fig. 1). The cDNA of gfap encoded a Kozak consensus sequence gccAUGG (Fig. 1; nucleotides from - 3 to +4$)$. The open reading frame encodes 457 amino acids long protein. The analysis showed also that the estimated molecular weight of the putative protein is $52.1 \mathrm{kDa}$ with a theoretical isoelectric point of 5.26. The predicted protein contains one putative functional Gfap homology intermediate filament domain: $90-398$ aa $\left(E\right.$ value $\left.=1.83 \mathrm{e}^{-126}\right)$. The length of the full deduced amino acid sequence of whitefish Gfap (457 aa) differs from the compared species' aa sequences by 27 ( $M$. musculus), 25 (H. sapiens), 14 (D. rerio), or is the same $(O$. mykiss and $S$. salar). A multiple alignment of the deduced whitefish Gfap protein sequence with those of other species retrieved from GenBank (Fig. 2) allowed the calculation pairwise identity score matrix which demonstrated that the whitefish Gfap protein shared 98\% identity with salmon and trout, $81 \%$ with zebrafish, and $63 \%$ with human and mouse. In addition, the neighbor-joining tree showed that whitefish Gfap clustered together with salmon and trout $(100 \%$ of bootstrap value) and then coalesced with zebrafish (87\%). The second group consisted of human and mouse, which formed another cluster with $100 \%$ frequency of occurrence. Together, these data suggest that whitefish Gfap is a structurally conserved aaggcatgtgtgtgcectgacggcttcattccetgec

$-38$

1 atggagagtcagagagtcetgtegtcttacaggaagcgtttcgggcaccagggggecggC $\begin{array}{llllllllllllllllllll}M & E & S & \& & R & V & L & S & S & Y & R & K & R & F & G & H & \& & G & A & G\end{array}$

61 agcgtgggtgggggettgaggetcagcagectctcetccagcegcetctccetccatggg

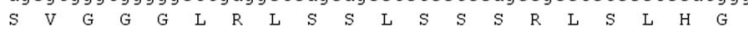

121 agcceccgceacat aacce actec agcaccatttcecgectctcectggggtcagetgga

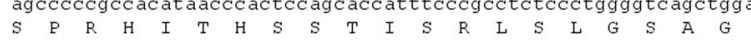

181 ggggecctgctcctggggaccctgggaaccggetggacttctcggetgactcactcctc $\begin{array}{llllllllllllllllllllllllllll}G & A & L & L & L & G & T & P & G & N & R & L & D & F & S & A & D & S & L & L\end{array}$

241 aaggcceagtatcgggagacgcgcaccaacgagaaggtggagatgatgggtctgaacgac $\begin{array}{lllllllllllllllllllll}K & A & \& & Y & R & E & T & R & T & N & E & K & V & E & M & M & G & L & N & D\end{array}$ cgcttcgecagctttatagagaaggtgcgcttcetggagcagcagaacacggtgctggtg $\begin{array}{lllllllllllllllllllllllllll}R & F & A & S & F & I & E & K & V & R & F & L & E & Q & \& & N & T & V & L & V\end{array}$ acggagetgaaccaactgagggggaaggagcecagecgtetcggggacatcttecaggag

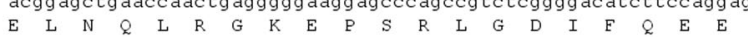

gaactgagggagctgcgcaggcaggtggacggactcagcgctgggaaggcceggctggag

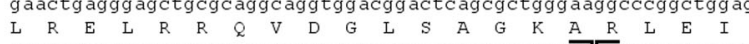

481 atagagagggacaacatggetgetgacatggecacgctcaaacagagretgcaagatgag $\begin{array}{lllllllllllllllllllll}E & R & D & N & M & A & A & D & M & A & T & L & K & \& & R & L & \& & D & E & M\end{array}$ atggttcttagacaggatgcagagagcaacttgaacacctttag acaggacgtggatgag $\begin{array}{llllllllllllllllllll}V & L & R & \& & D & A & E & S & N & L & N & T & F & R & \& & D & V & D & E & A\end{array}$ gcatctctgaaccgtgtccagttggagaggaagatagacgegetgcaggatgaatcgcC $S$ L N R V \& I E R K I D A I \& D E I A ttcctcaagaagatccacgagga L K I H Caggtccatgtggatctggacgtgtccaagccagacctgaccgctgetctgaggac $V$. $\begin{array}{llllllllllllllllllll}V & H & V & D & L & D & V & S & K & P & D & L & T & A & A & L & R & D & I & R\end{array}$ 781 cgggtccagtatgagtctgtggcctcctctaacattcaggagacagaagagtggtaccgc $\begin{array}{llllllllllllllllllll}V & \& & Y & E & S & V & A & S & S & N & I & \& & E & T & E & E & W & Y & R & S\end{array}$ tccaagtt tgcegacttgacegacgeagceactcggaatgcagacgecttgegattggec

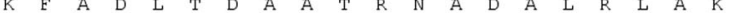
aaacagg agggcaacg agtaccgccggcaactccaggccatgacetgtgacatggaggca

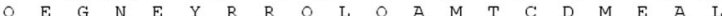
$\&$ C P $R$ T $T$. gtggagacggctggtt accaggat acggtgggtcatctggaggaggagatccag accetg $\begin{array}{lllllllllllllllllllll}E & T & A & G & Y & \& & D & T & V & G & H & L & E & E & E & I & \& & T & L & K\end{array}$

1081 aaggaggggatggecagacacctgcaggagtaccaggacctgetcaacgtcaaactggcc $\begin{array}{llllllllllllllllllllllll}E & G & M & A & R & H & \text { L } & \& & E & Y & \& & D & \text { L } & \text { L } & \text { N } & \text { V } & \text { K } & \text { L } & \text { A } & \text { L }\end{array}$ ctggac at ag ag atcgecacct ac agg aagctgetggagggagagg ag agc agfyat tcact $\begin{array}{llllllllllllllllllll}D & I & E & I & A & T & Y & R & K & L & L & E & G & E & E & S & R & I & T & V\end{array}$ gttccaatgcagagcttctctaacctgcagttcagaglagaccagtatggacactaagttc $\begin{array}{llllllllllllllllllll}P & M & \& & S & F & S & N & L & \& & F & R & E & T & S & M & D & T & K & F & S\end{array}$ tctccagaggcec atgtcaagaggagcatcat agtgcggactgtgg agact ag ag acggg $\begin{array}{lllllllllllllllllllll}P & E & A & H & V & K & R & S & I & I & V & R & T & V & E & T & R & D & G & E\end{array}$

gagatcattaaggagtctacggctgagaggaaggagattcctgacagtccttaaggaca I $I \begin{array}{llllllllllllllllllllllll} & K & E & S & T & A & E & R & K & E & I & P & D & S & P & *\end{array}$

1381 catggtgetagetatgtetgtcac actgtececactceacagt aacgettggaggecttg

1441 catgataatgataccetttcctgacaaggeacctccetctctccaaacctcaagtcag

1501 ttgetaccacctcaccatccettectcectcteatcat aatcaccccag accatgt

1561 tacatcattaaatactaggagttttgttgaaactcaaataaatccetcattgcatctt

1621 gttagcactttgecaaaagtattattttetattactgtaactgtagettgagtgtge

1681 ttgtagataggctttagtgctaggacgtttggcettgcaccttagaaggaaggtcttgg

1741 actactaccettgtgattaacagacttcatgctgggaatgtatttettgttcagctca

1801 taat agtgacagatcagagtgggaatgttctcattgtgtttggatagtagccagagagg

1861 aggecttgaatgtagtgactgttattcagctggtggcaggggtcatgetgaagttgtgt

1921 ggtttgagtggatgtgagaagtcaagaggaagtacagttgctggggttagcagtggaca 1981 ggatgggtctcagacaaggaagatgatgtgtgttcgacagtgcttttggcagactgttg

2041 gtgaaataagctgatttaaccetcctccagggccaaacaccatatctatttcatccctc

2101 catcatacceccecceccec

Fig. 1 Nucleotide sequence of cDNA of whitefish gfap aligned with deduced amino acid sequence (GenBank accession no. MG182670). Predicted exon-exon junctions and predicted MiR124-3p binding site (MiR124-3p-BS) are indicated

protein, which retains functional features characteristic for intermediate filament protein.

\section{A MiR124-3p Target Site Is Present in the 3'UTR of $g$ fap in Whitefish}

One of the objectives of our study was to investigate whether the 3'UTR of gfap in whitefish contains a putative MiR124-3p 


O.mykiss
S.salar
C.lavatetus
D.rerio
H.sapiens
M.musculus

O.mykiss
S.salar
C.lavaretus
D.rerio
H.sapiens
M.musculus


O.mykiss
S. salar
C.lavaretus
D.rerio
H.sapiens
M.musculus
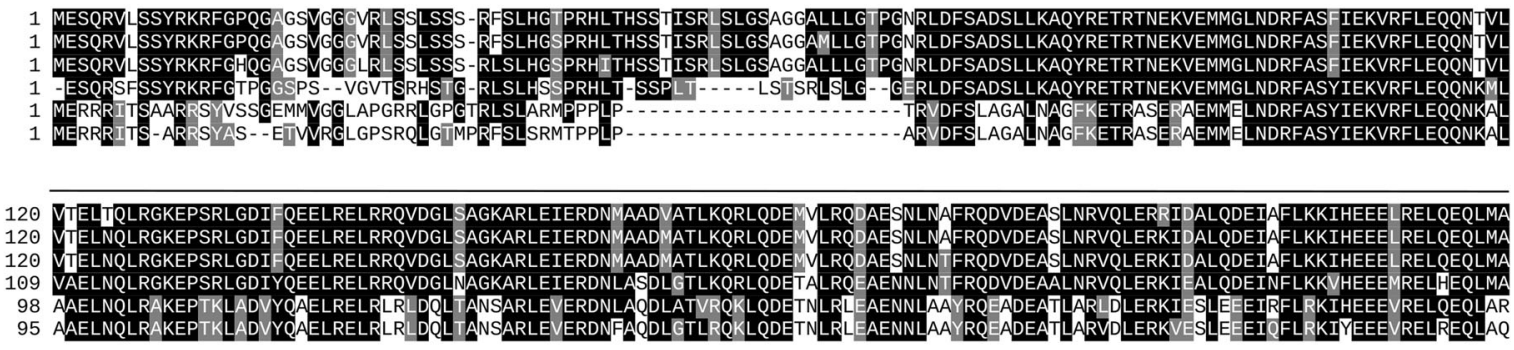

musculus

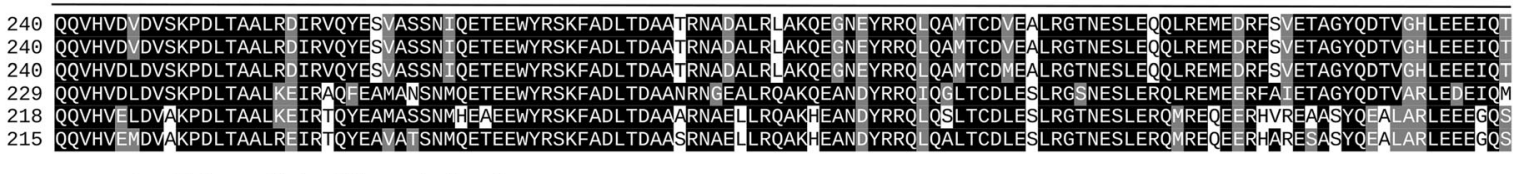

<-- Intermediate filament domain

o.mykiss

S. salar

C. lavaretus

D. rerio

H. sapiens

M.musculus

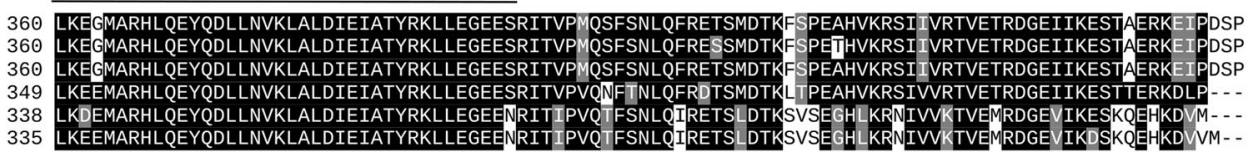

Fig. 2 Multiple alignment of deduced amino acid sequence for whitefish Gfap with those for other species. The alignment was built using Clustal $\mathrm{W}$ and presented using BoxShade. Identical residues are white letters in

black boxes, while conservative substitutions are shaded in gray. The Gfap-conserved functional domains are indicated on the top of the region response element(s). In silico analysis, using Segal Lab software identified one MiR124-3p target site within the analyzed 3'UTR sequence (Fig. 1). The strength of the potential miRNA:mRNA interaction could be estimated in terms of the minimum free energy for hybridization $(\Delta \mathrm{G})$, which for the predicted target site equals $-14.9 \mathrm{~mol}^{-1}$. Figure 3 a shows the putative base-pairing between mature MiR124-3p and its predicted target region within the $3^{\prime} \mathrm{UTR}$ of whitefish gfap mRNA. The degree of complementarity to the seed region (nucleotides 2, 3, 5, 6, and 7 of microRNA) classifies this target site into the so-called GUT moderate-stringent seed class, which contains one G:U wobble with the uracil on the target site of mRNA (Saito and Sætrom 2010).

\section{gfap Is Up-regulated from the 7th Day of Exposure to MC-LR}

Starting on the 7 th day of exposure, we observed upregulation of gfap expression relative to the untreated control groups (Fig. 4a). While the differences between gfap expression levels were significant at 7 days after injection $(p=$ $0.016)$, those observed until the last day of experiment were not: 14 days $(p=0.065)$ and 28 days $(p=0.084)$. This upregulation of gfap expression may serve as a defense mechanism against MC-LR.

At the same time, MiR124-3p levels in the whitefish brains remained unchanged (Fig. 4b) so as plasma levels of this miRNA (Fig. 4c), which suggest no functional correlation between gfap and MiR124-3p expression levels in MC-LR triggered toxicity in whitefish.

\section{The 3'UTR of Whitefish gfap Is Not a Functional Target of MiR124-3p In Vitro}

In order to verify the findings from in vivo experiment, we performed dual-luciferase reporter assay. This is the first study to investigate whether gfap is negatively regulated by MiR124-3p. Cotransfection of HEK-293T with the gfap-3' UTR-wt luciferase reporter plasmid and MiR124-3p mimic did not lead to any inhibition of luciferase activity. The same results were observed with gfap-3'UTR-mut construct. These data show that studied gfap 3'UTR was not a direct target for MiR124-3p in vitro (Fig. 3b).

\section{Discussion}

This study investigates the possibility of functional correlation between gfap and MiR124-3p expression in MC-LR-exposed whitefish, and the suitability of plasma MiR124-3p as a potential biomarker of brain injury. We found that $\mathrm{MC}$ LR induced the expression of gfap mRNA from the 7 th day of the exposure period and kept it slightly elevated to the end of the treatment. This indicates that MC-LR may induce functional changes in the brain of whitefish that could be caused due to injury of that organ. Although MCs are primarily considered to be hepatotoxins, several studies have demonstrated that MC exposure causes a variety of symptoms related to neurotoxic effects (reviewed in Florczyk et al. 2014). For example, MC-LR exposure produced inflammatory effects in rat brains: astrocyte hyperplasia 
a)

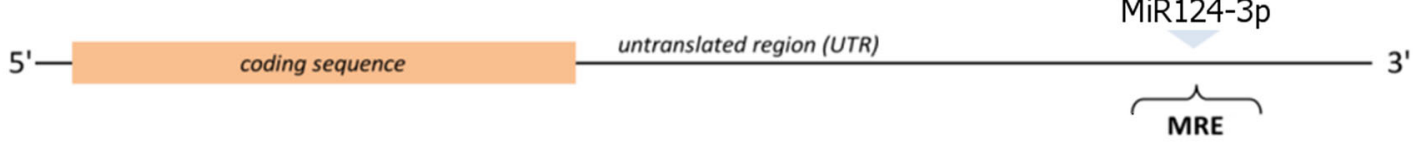

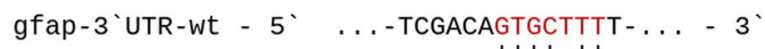

MiR124-3p - 3 ...-GUGGCGCACGGAAU- - 5

$\mathrm{dG}=-14.9 \mathrm{kcal} \cdot \mathrm{mol}^{-1}$

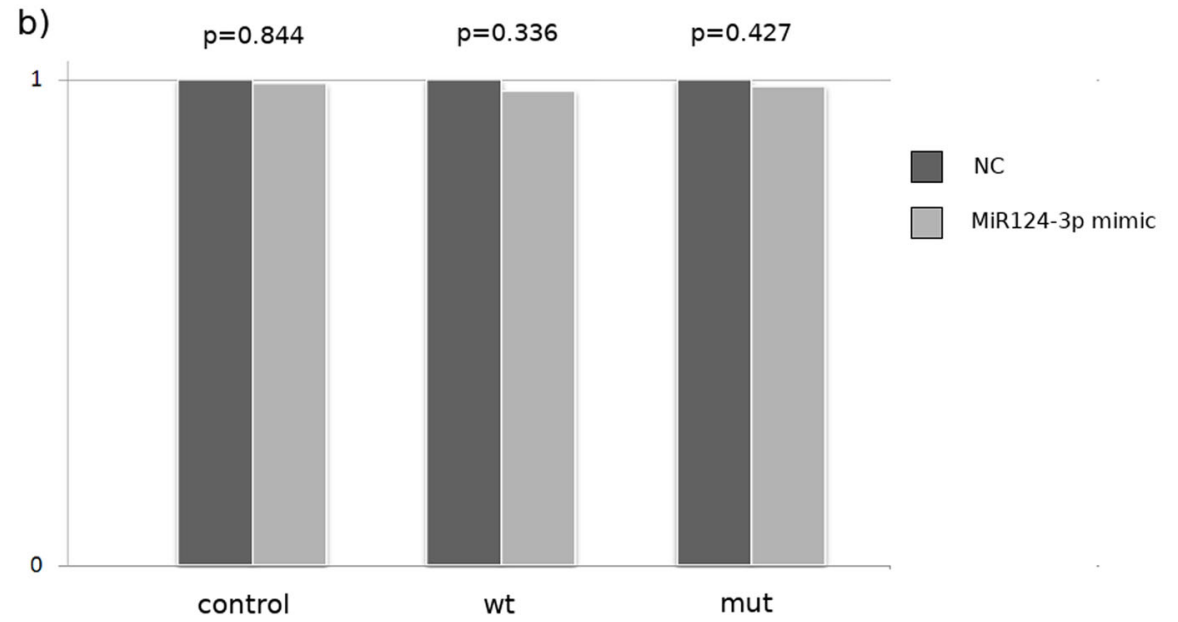

Fig. 3 Whitefish gfap 3'UTR is not a functional target of MiR124-3p in vitro. a Diagram of the MiR124-3p putative binding sites in the $3^{\prime} U T R$ of gfap. b Effects of MiR124-3p mimic on the expression of gfap 3'-UTRcontaining reporter genes (wt, wild type; mut, mutant type). Each

and increased expression of Gfap protein, which indicated that astrocytes actively respond to the toxicity of MCs ( $\mathrm{Li}$ et al. 2014). Reactive astrocytes not only secrete inflammatory mediators and chemokines that contribute to inflammationmediated CNS damage (Meeuwsen et al. 2003) but also produce inflammatory cytokines and chemokines that contribute to reparative processes in the early stages of neuroinflammation (Sharma et al. 2007). Similarly, in the liver of whitefish exposed to MC-LR, numerous macrophages were present on the 7th day of the exposure period, indicating that cell debris from cell damage were being removed and that liver regeneration was beginning (Woźny et al. 2016). Activated macrophages produce cytokines, such as TNF-a, which is mainly involved in the systemic inflammation response, but also in apoptosis, cell proliferation, and cell differentiation (Hehlgans and Pfeffer 2005). Besides inflammation, MC-LR exerts whole brain cytotoxicity (Feurstein et al. 2009), inducing neuronal apoptosis and degrading the neurite network (Feurstein et al. 2011). As shown recently in rats' astrocytes, cytoskeletal disruption seen by the degradation of GFAP occurred after exposure to various MC variants (Bulc Rozman et al. 2017). Similarly, in the liver of whitefish, cytotoxicity was revealed in disruption of endoplasmic reticulum, chromatin, and cytoskeleton (Woźny et al. 2016). Although the current study does not include ultrastructural images of whitefish brain, it was luciferase activity was normalized to the value obtained in the cells transfected with NC mimics. Results were represented as mean \pm S.D. from three independent experiments, each prepared in quadruplicate

reasonable to assume, based on the above-mentioned studies, that similar effects could have emerged. The present study demonstrates that repeated intraperitoneal injection of MCLR induced neuronal toxicity was depicted in elevated $g$ fap expression, which could be associated with inflammatory reactions in the midbrain.

Although gfap mRNA expression in the brain was elevated at the 7th day of exposure period, MiR124-3p remained unchanged. This suggests no functional correlation between gfap and MiR124-3p expression levels in MC-LR triggered toxicity in whitefish. MiR124-3p seems to play a crucial role in brain development as well it is enriched in mature brain tissue. Besides important roles in neuronal regulation, MiR124 is closely associated with the development of some CNS diseases. Abnormal expression of MiR124 has been shown to be implicated in many CNS diseases, like Alzheimer's disease, brain tumor, cerebral ischemic stroke, and Parkinson's disease (Sun et al. 2015). In Parkinson's disease, MiR124-3p prevented various pathological processes including neurotoxicity, neuronal apoptosis, neuroinflammation, and oxidative stress (Geng et al. 2017). MiR124-3p overexpression attenuated neuronal injury (displayed as increased cell viability and superoxide dismutase activity), as well as reduced cell apoptosis, Caspase-3 activity, lactate dehydrogenase activity, 
Fig. 4 Expression ratio of a $g f a p$ in midbrain, $\mathbf{b}$ MiR124-3p in midbrain, and $\mathbf{c}$ MiR124-3p in plasma of whitefish exposed for 28 days to microcystin (MC-LR) at a dose of $100 \mathrm{\mu g} \mathrm{kg}^{-1}$ (orange squares), relative to control (blue circles). Intraperitoneal injections of MC-LR were given on days 0 , 7,14 , and 21. Points present values obtained from individual fish within a specific group, whereas horizontal lines indicate mean values ( $n=6$ per group) relative to control at the respective exposure period. Asterisks indicate significant differences from the control group at that time (treatment-dependent changes; $* p<0.05)$ a) Brain gfap

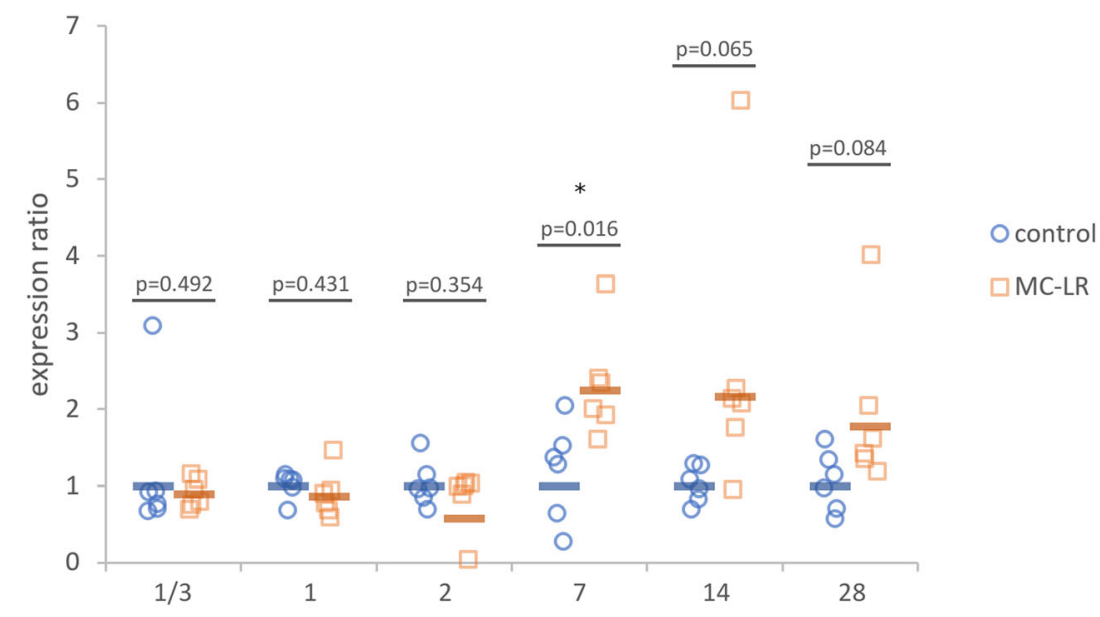

b) Brain MiR124-3p

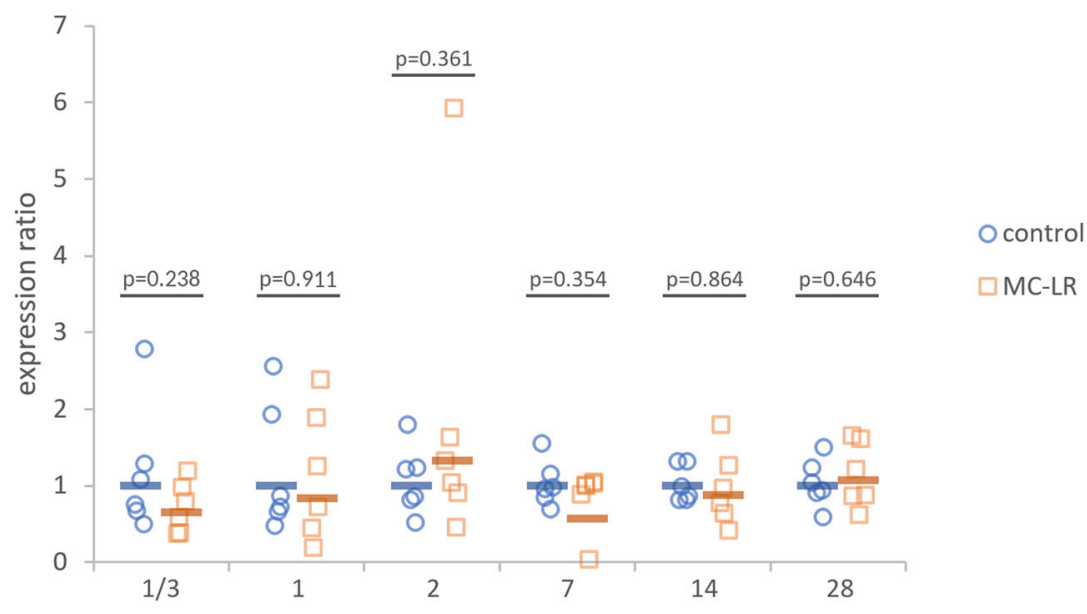

c) Plasma MiR124-3p

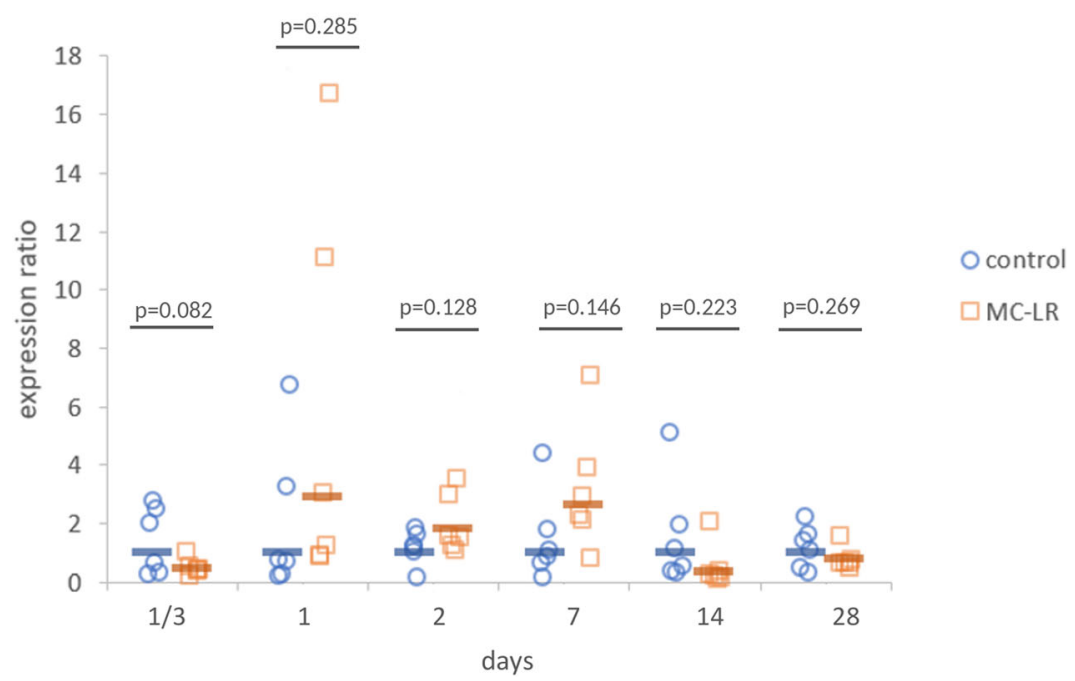

inflammatory factors TNF- $\alpha$ and IL- $1 \beta$ levels, and reactive oxygen species generation (Geng et al. 2017). Possible regulation of the glial scar by MiR124 has been reported by Doeppner et al. (2013) and more recently by Hamzei Taj et al. (2016). MiR124 participated in this process, by increasing expression of Arg- 1 or TGF- $\beta$ in microglia and 
macrophages, which in turn modulated the reactive astrocytes by the secretion of cytokines and chemokines. On the other hand, MiR124 effectively silenced human GFAP promoter expression by targeting its 3'UTR (Taschenberger et al. 2017). Moreover, it has been shown that MiR124 overexpression indirectly suppressed the expression of GFAP (Jiao et al. 2017). Our results showed an unchanged expression profile of MiR124-3p during the exposure period, proving that MC-LRinduced changes in gfap expression in whitefish is not correlated with participation of this miRNA.

It is accepted that circulating miRNAs are either byproducts of microvesicle secretion or cell death. Extracellular circulating miRNAs are mostly microvesicles free and associated with the RNA-binding Argonaute proteins (Ago), which are thought to be released into the circulation from the cytoplasm of necrotic cells due to disruption of cellular membranes (Sohel 2016). Thus, tissue-specific miRNAs are promising biomarkers of monitoring tissue injury. In this study, plasma levels of MiR124-3p in MC-LR exposed whitefish were unchanged during exposure period which excludes this miRNA as a biomarker of brain injury in fish. Both acetaminophen (APAP) and MC-LR induce acute liver injury in mammals and fish. Drug-induced liver injury can be monitored through traditional blood enzymes (ALT, AST) or more sensitively through miRNA quantification. Our previous study on whitefish exposed to MC-LR showed increased liver-specific miRNA plasma levels in fish, which is similar to the outcome acetaminophen induced in mammals (Florczyk et al. 2016). MiR122-5p levels were elevated as early as $8 \mathrm{~h}$ after exposure. This following study aimed to examine if MCLR-induced brain injury could also be monitored using brainspecific MiR124-3p. Recent study on evaluating MiR124 as a marker of acetaminophen-induced brain injury in pigs demonstrated increased levels of this miRNA in blood (Baker et al. 2015). However, the release of MiR124 into the plasma was likely to be due to relative ischemia, as increased levels of MiR124 were significantly elevated only when cerebral perfusion pressure (CPP) fell below $30 \mathrm{mmHg}$. This could be related to indirect acetaminophen-induced brain injury caused by ischemia and general organ failure (Baker et al. 2015). In the present study, repeated exposure of whitefish to a subacute dose of MC-LR could not induce similar changes.

Luciferase reporter assay confirmed the lack of interaction in vitro which shows that MiR124-3p is unlikely to regulate gfap expression. This is the first study to investigate whether whitefish gfap is negatively regulated by MiR124-3p; however, our prediction of potential MiR124-3p target sites in 3'UTR of gfap could have been not accurate. For our analysis, we used miRNA prediction tool developed by Segal Lab, which has found only one moderate-stringent seed class MiR124-3p binding site. This miRNA seed class is considered as a weaker binding site than most commonly used in reporter assays 7-mer-m8 seed class. Therefore for our in vitro analysis, with only one binding site present, we have used the whole whitefish gfap 3'UTR sequence.

This prevented any false negative results even if our prediction was not completely correct and stronger MiR124-3p binding sites are present in gfap 3'UTR.

In conclusion, our study demonstrates that the exposure of whitefish to MC-LR-induced expression of gfap mRNA but did not involve any changes in expression of MiR124-3p in whitefish brain, contributing to our understanding of the mechanistic role of miRNAs in MC-LR neurotoxicity. In addition, we show that the expression of MiR124-3p in whitefish brain and plasma is not correlated with the changes of gfap mRNA expression and thus cannot be considered as a biomarker of brain injury induced by MC-LR. Furthermore, by using luciferase reporter assay, we confirmed the lack of interaction between 3'UTR of gfap mRNA and MiR124-3p, which rules out the possibility of their direct regulatory relationship. Further research focusing on regulation of astrocyte reactivity could provide better understanding of molecular background underlying MC-LR-induced neurotoxicity and perhaps hold promise for prevention strategy for MC-LR intoxication.

Acknowledgements We thank Prof. Stefan Dobosz from the Department of Salmonid Research in Rutki, Inland Fisheries Institute in Olsztyn, Poland, for his excellent technical assistance during hatchery operations. The authors also thank Mark Leonard for proofreading the manuscript. The study was supported by research grant from National Science Centre (Poland) No. DEC-2014/15/N/NZ9/01471.

Funding This study was funded by the National Science Centre (Poland) (grant number DEC-2014/15/N/NZ9/01471).

\section{Compliance with Ethical Standards}

Ethical Approval All applicable international, national, and/or institutional guidelines for the care and use of animals were followed.

Conflict of Interest The authors declare that they have no conflict of interest.

Open Access This article is distributed under the terms of the Creative Commons Attribution 4.0 International License (http:// creativecommons.org/licenses/by/4.0/), which permits unrestricted use, distribution, and reproduction in any medium, provided you give appropriate credit to the original author(s) and the source, provide a link to the Creative Commons license, and indicate if changes were made.

\section{References}

Abidin SZ, Leong J-W, Mahmoudi M, Nordin N, Abdullah S, Cheah P-S, Ling K-H (2017) In silico prediction and validation of Gfap as an miR-3099 target in mouse brain. Neurosci Bull 33:373-382. https:// doi.org/10.1007/s12264-017-0143-0 
Arukwe A (2006) Toxicological housekeeping genes: do they really keep the house? Environ Sci Technol 40:7944-7949

Baganz D, Staaks G, Steinberg C (1998) Impact of the cyanobacteria toxin, microcystin-LR on behaviour of zebrafish, Danio rerio. Water Res 32:948-952

Baganz D, Staaks G, Pflugmacher S, Steinberg CEW (2004) Comparative study of microcystin-LR-induced behavioral changes of two fish species, Danio rerio and Leucaspius delineatus. Environ Toxicol 19:564-570. https://doi.org/10.1002/tox.20063

Baker LA, Lee KCL, Palacios Jimenez C, Alibhai H, Chang Y-M, Leckie PJ, Mookerjee RP, Davies NA, Andreola F, Jalan R (2015) Circulating microRNAs reveal time course of organ injury in a porcine model of acetaminophen-induced acute liver failure. PLoS One 10:e0128076. https://doi.org/10.1371/journal.pone.0128076

Bartel DP (2004) MicroRNAs: genomics, biogenesis, mechanism, and function. Cell 116:281-297. https://doi.org/10.1016/S00928674(04)00045-5

Biggar KK, Wu CW, Storey KB (2014) High-throughput amplification of mature microRNAs in uncharacterized animal models using polyadenylated RNA and stem-loop reverse transcription polymerase chain reaction. Anal Biochem 462:32-34. https://doi.org/10. 1016/j.ab.2014.05.032

Brenner M (2014) Role of GFAP in CNS injuries. Neurosci Lett 565:713. https://doi.org/10.1016/j.neulet.2014.01.055

Brzuzan P, Woźny M, Wolińska L, Piasecka A (2012) Expression profiling in vivo demonstrates rapid changes in liver microRNA levels of whitefish (Coregonus lavaretus) following microcystin-LR exposure. Aquat Toxicol 122-123:188-196. https://doi.org/10.1016/j. aquatox.2012.07.001

Brzuzan P, Florczyk M, Łakomiak A, Woźny M (2016) Illumina sequencing reveals aberrant expression of microRNAs and their variants in whitefish (Coregonus lavaretus) liver after exposure to microcystinLR. PLoS One 11:e0158899. https://doi.org/10.1371/journal.pone. 0158899

Bulc Rozman K, Jurič DM, Šuput D (2017) Selective cytotoxicity of microcystins LR, LW and LF in rat astrocytes. Toxicol Lett 265:18. https://doi.org/10.1016/j.toxlet.2016.11.008

Cazenave J, Nores ML, Miceli M, Díaz MP, Wunderlin DA, Bistoni MA (2008) Changes in the swimming activity and the glutathione Stransferase activity of Jenynsia multidentata fed with microcystinRR. Water Res 42:1299-1307. https://doi.org/10.1016/j.watres. 2007.09.025

Chang T-H, Huang H-Y, Hsu JB-K, Weng S-L, Horng J-T, Huang H-D (2013) An enhanced computational platform for investigating the roles of regulatory RNA and for identifying functional RNA motifs. BMC Bioinformatics 14:S4-S8. https://doi.org/10.1186/14712105-14-S2-S4

Doeppner TR, Doehring M, Bretschneider E, Zechariah A, Kaltwasser B, Müller B, Koch JC, Bähr M, Hermann DM, Michel U (2013) MicroRNA-124 protects against focal cerebral ischemia via mechanisms involving Usp14-dependent REST degradation. Acta Neuropathol (Berl) 126:251-265. https://doi.org/10.1007/s00401013-1142-5

Feurstein D, Holst K, Fischer a DDR (2009) Oatp-associated uptake and toxicity of microcystins in primary murine whole brain cells. Toxicol Appl Pharmacol 234:247-255. https://doi.org/10.1016/j. taap.2008.10.011

Feurstein D, Stemmer K, Kleinteich J, Speicher T, Dietrich DR (2011) Microcystin congener- and concentration-dependent induction of murine neuron apoptosis and neurite degeneration. Toxicol Sci Off J Soc Toxicol 124:424-431. https://doi.org/10.1093/toxsci/kfr243

Florczyk M, Łakomiak A, Woźny M, Brzuzan P (2014) Neurotoxicity of cyanobacterial toxins. Environ Biotechnol 10:26-43. https://doi.org/ 10.14799/ebms246

Florczyk M, Brzuzan P, Krom J, Woźny M, Łakomiak A (2016) miR$122-5 p$ as a plasma biomarker of liver injury in fish exposed to
microcystin-LR. J Fish Dis 39:741-751. https://doi.org/10.1111/ jfd. 12406

Friedman RC, Farh KK-H, Burge CB, Bartel DP (2009) Most mammalian mRNAs are conserved targets of microRNAs. Genome Res 19: 92-105. https://doi.org/10.1101/gr.082701.108

Gasteiger E, Hoogland C, Gattiker A, Duvaud S, Wilkins MR, Appel RD, Bairoch A (2005) Protein identification and analysis tools on the ExPASy server. In: The proteomics protocols handbook. Humana Press, pp 571-607

Geng L, Liu W, Chen Y (2017) miR-124-3p attenuates MPP+-induced neuronal injury by targeting STAT3 in SH-SY5Y cells. Exp Biol Med Maywood NJ 242:1757-1764. https://doi.org/10.1177/ 1535370217734492

Guo L, Sun B, Sang F, Wang W, Lu Z (2009) Haplotype distribution and evolutionary pattern of miR-17 and miR-124 families based on population analysis. PLoS One 4:e7944. https://doi.org/10.1371/ journal.pone.0007944

Hamzei Taj S, Kho W, Riou A, Wiedermann D, Hoehn M (2016) MiRNA-124 induces neuroprotection and functional improvement after focal cerebral ischemia. Biomaterials 91:151-165. https://doi. org/10.1016/j.biomaterials.2016.03.025

Hehlgans T, Pfeffer K (2005) The intriguing biology of the tumour necrosis factor/tumour necrosis factor receptor superfamily: players, rules and the games. Immunology 115:1-20. https://doi.org/10. $1111 / j .1365-2567.2005 .02143 . x$

Jiao S, Liu Y, Yao Y, Teng J (2017) miR-124 promotes proliferation and differentiation of neuronal stem cells through inactivating Notch pathway. Cell Biosci 7:68. https://doi.org/10.1186/s13578-0170194-y

Kapsimali M, Kloosterman WP, de Bruijn E, Rosa F, RH a P, Wilson SW (2007) MicroRNAs show a wide diversity of expression profiles in the developing and mature central nervous system. Genome Biol 8: R173. https://doi.org/10.1186/gb-2007-8-8-r173

Lagos-Quintana M, Rauhut R, Yalcin A, Meyer J, Lendeckel W, Tuschl T (2002) Identification of tissue-specific microRNAs from mouse. Curr Biol 12:735-739. https://doi.org/10.1016/S0960-9822(02) 00809-6

Łakomiak A, Brzuzan P, Jakimiuk E, Florczyk M, Woźny M (2016) miR34a and bcl-2 expression in whitefish (Coregonus lavaretus) after microcystin-LR exposure. Comp Biochem Physiol B Biochem Mol Biol 193:47-56. https://doi.org/10.1016/j.cbpb.2015.12.005

Landgraf P, Rusu M, Sheridan R, Sewer A, Iovino N, Aravin A, Pfeffer S, Rice A, Kamphorst AO, Landthaler M, Lin C, Socci ND, Hermida L, Fulci V, Chiaretti S, Foà R, Schliwka J, Fuchs U, Novosel A, Müller R-U, Schermer B, Bissels U, Inman J, Phan Q, Chien M, Weir DB, Choksi R, de Vita G, Frezzetti D, Trompeter HI, Hornung V, Teng G, Hartmann G, Palkovits M, di Lauro R, Wernet P, Macino G, Rogler CE, Nagle JW, Ju J, Papavasiliou FN, Benzing T, Lichter P, Tam W, Brownstein MJ, Bosio A, Borkhardt A, Russo JJ, Sander C, Zavolan M, Tuschl T (2007) A mammalian microRNA expression atlas based on small RNA library sequencing. Cell 129:14011414. https://doi.org/10.1016/j.cell.2007.04.040

Larkin MA, Blackshields G, Brown NP, Chenna R, McGettigan PA, McWilliam H, Valentin F, Wallace IM, Wilm A, Lopez R, Thompson JD, Gibson TJ, Higgins DG (2007) Clustal W and Clustal X version 2.0. Bioinformatics 23:2947-2948. https://doi. org/10.1093/bioinformatics/btm404

Letunic I, Doerks T, Bork P (2015) SMART: recent updates, new developments and status in 2015. Nucleic Acids Res 43:D257-D260. https://doi.org/10.1093/nar/gku949

Li X-B, Zhang X, Ju J, Li Y, Yin L, Pu Y (2014) Alterations in neurobehaviors and inflammation in hippocampus of rats induced by oral administration of microcystin-LR. Environ Sci Pollut Res 21:12419-12425. https://doi.org/10.1007/s11356-014-3151-x

Marchler-Bauer A, Derbyshire MK, Gonzales NR, Lu S, Chitsaz F, Geer LY, Geer RC, He J, Gwadz M, Hurwitz DI, Lanczycki CJ, Lu F, 
Marchler GH, Song JS, Thanki N, Wang Z, Yamashita RA, Zhang D, Zheng C, Bryant SH (2015) CDD: NCBI's conserved domain database. Nucleic Acids Res 43:D222-D226. https://doi.org/10. 1093/nar/gku1221

Meeuwsen S, Persoon-Deen C, Bsibsi M, Ravid R, Noort JMV (2003) Cytokine, chemokine and growth factor gene profiling of cultured human astrocytes after exposure to proinflammatory stimuli. Glia 43:243-253. https://doi.org/10.1002/glia.10259

Middeldorp J, Hol EM (2011) GFAP in health and disease. Prog Neurobiol 93:421-443. https://doi.org/10.1016/j.pneurobio.2011. 01.005

Mishima T, Mizuguchi Y, Kawahigashi Y, Takizawa T, Takizawa T (2007) RT-PCR-based analysis of microRNA (miR-1 and -124) expression in mouse CNS. Brain Res 1131:37-43. https://doi.org/10. 1016/j.brainres.2006.11.035

Mitchell A, Chang H-Y, Daugherty L, Fraser M, Hunter S, Lopez R, McAnulla C, McMenamin C, Nuka G, Pesseat S, SangradorVegas A, Scheremetjew M, Rato C, Yong S-Y, Bateman A, Punta M, Attwood TK, Sigrist CJA, Redaschi N, Rivoire C, Xenarios I, Kahn D, Guyot D, Bork P, Letunic I, Gough J, Oates M, Haft D, Huang H, Natale DA, Wu CH, Orengo C, Sillitoe I, Mi H, Thomas PD, Finn RD (2015) The InterPro protein families database: the classification resource after 15 years. Nucleic Acids Res 43:D213D221. https://doi.org/10.1093/nar/gku1243

Moxon S, Jing R, Szittya G, Schwach F, Pilcher RLR, Moulton V, Dalmay T (2008) Deep sequencing of tomato short RNAs identifies microRNAs targeting genes involved in fruit ripening. Genome Res 18:1602-1609. https://doi.org/10.1101/gr.080127.108

Pfaffl MW, Horgan GW, Dempfle L (2002) Relative expression software tool (REST) for group-wise comparison and statistical analysis of relative expression results in real-time PCR. Nucleic Acids Res 30: e36-e336

Pogue AI, Cui JG, Li YY, Zhao Y, Culicchia F, Lukiw WJ (2010) Micro RNA-125b (miRNA-125b) function in astrogliosis and glial cell proliferation. Neurosci Lett 476:18-22. https://doi.org/10.1016/j. neulet.2010.03.054

Saito T, Sætrom P (2010) MicroRNAs - targeting and target prediction. New Biotechnol 27:243-249. https://doi.org/10.1016/j.nbt.2010.02. 016

Saraiva C, Paiva J, Santos T, Ferreira L, Bernardino L (2016) MicroRNA124 loaded nanoparticles enhance brain repair in Parkinson's disease. J Control Release 235:291-305. https://doi.org/10.1016/j. jconrel.2016.06.005

Saul N, Chakrabarti S, Stürzenbaum SR, Menzel R, Steinberg CEW (2014) Neurotoxic action of microcystin-LR is reflected in the transcriptional stress response of Caenorhabditis elegans. Chem Biol Interact 223:51-57. https://doi.org/10.1016/j.cbi.2014.09.007

Sharma V, Mishra M, Ghosh S, Tewari R, Basu A, Seth P, Sen E (2007) Modulation of interleukin-1beta mediated inflammatory response in human astrocytes by flavonoids: implications in neuroprotection. Brain Res Bull 73:55-63. https://doi.org/10.1016/j.brainresbull. 2007.01.016

Sofroniew MV, Vinters HV (2010) Astrocytes: biology and pathology. Acta Neuropathol (Berl) 119:7-35. https://doi.org/10.1007/s00401009-0619-8

Sohel MH (2016) Extracellular/circulating microRNAs: release mechanisms, functions and challenges. Achiev Life Sci 10:175-186. https://doi.org/10.1016/j.als.2016.11.007

Spachmo B, Arukwe A (2012) Endocrine and developmental effects in Atlantic salmon (Salmo salar) exposed to perfluorooctane sulfonic or perfluorooctane carboxylic acids. Aquat Toxicol 108:112-124. https://doi.org/10.1016/j.aquatox.2011.07.018

Sun Y, Luo Z-M, Guo X-M, Su D-F, Liu X (2015) An updated role of microRNA-124 in central nervous system disorders: a review. Front Cell Neurosci 9. https://doi.org/10.3389/fncel.2015.00193

Tamura K, Stecher G, Peterson D, Filipski A, Kumar S (2013) MEGA6: molecular evolutionary genetics analysis version 6.0. Mol Biol Evol 30:2725-2729. https://doi.org/10.1093/molbev/mst197

Taschenberger G, Tereshchenko J, Kügler S (2017) A microRNA124 target sequence restores astrocyte specificity of gfaABC1D-driven transgene expression in AAV-mediated gene transfer. Mol Ther Nucleic Acids 8:13-25. https://doi.org/10.1016/j.omtn.2017.03.009

Wang M, Chan LL, Si M, Hong H, Wang D (2010) Proteomic analysis of hepatic tissue of zebrafish (Danio rerio) experimentally exposed to chronic microcystin-LR. Toxicol Sci Off J Soc Toxicol 113:60-69. https://doi.org/10.1093/toxsci/kfp248

Wang C-Y, Yang S-H, Tzeng S-F (2015) MicroRNA-145 as one negative regulator of astrogliosis: role of mir-145 in astrocytic dynamics. Glia 63:194-205. https://doi.org/10.1002/glia.22743

Wheeler DL, Church DM, Edgar R, Federhen S, Helmberg W, Madden TL, Pontius JU, Schuler GD, Schriml LM, Sequeira E, Suzek TO, Tatusova TA, Wagner L (2004) Database resources of the National Center for Biotechnology Information: update. Nucleic Acids Res 32:D35-D40. https://doi.org/10.1093/nar/gkh073

Woźny M, Lewczuk B, Ziółkowska N, Gomułka P, Dobosz S, Łakomiak A, Florczyk M, Brzuzan P (2016) Intraperitoneal exposure of whitefish to microcystin-LR induces rapid liver injury followed by regeneration and resilience to subsequent exposures. Toxicol Appl Pharmacol 313:68-87. https://doi.org/10.1016/j.taap.2016.10.014 